\title{
How Do Developmental and Accommodative HRM Enhance Employee Engagement and Commitment? The Role of Psychological Contract and SOG Strategies
}

\section{P. Matthijs Bal, Dorien T. A. M. Kooij and Simon B. De Jong}

VU University Amsterdam; Tilburg University; EADA Barcelona

ABSTRACT In the context of the changing workforce, this study introduced two perspectives on HRM and distinguished universalistic developmental HRM from contingent accommodative HRM. We predicted two separate pathways for the effects on two employee outcomes: work engagement and affective commitment. We expected that developmental HRM would universally relate to employee outcomes by rebalancing the psychological contract between the employee and organization into a less transactional to a more relational contract. We also predicted that accommodative HRM would relate to outcomes only when fulfilling specific needs of employees, associated with their selecting, optimizing, and compensating strategies. Results of a multilevel study among 1058 employees in 17 healthcare units fully supported our expectations regarding the role of the psychological contract. Additionally, we found support for the expected roles of selection and compensation, but not for optimization strategy. This study contributes to the literature by demonstrating that HRM relates to employee outcomes through multiple pathways, which can be either universal or contingent.

Keywords: accommodative HRM, affective commitment, developmental HRM, employee work engagement, selection, optimization and compensation (SOC) theory, transactional and relational psychological contract

\section{INTRODUGTION}

Increasing employee engagement and commitment has traditionally been high on the agenda of Human Resource departments. Research indicates that having an engaged and committed workforce can lead to numerous beneficial outcomes, such as lower turnover intentions (Allen et al., 2003) and higher organizational performance (e.g. Harrison et al., 2006; Harter et al., 2002; Whitman et al., 2010). These employee outcomes are becoming

Address for reprints: P. Matthijs Bal, Management \& Organization, VU University Amsterdam, De Boelelaan 1105, 1081 HV Amsterdam, The Netherlands (p.m.bal@vu.nl). 
increasingly important due to the aging workforce, as demographic changes make it more difficult for organizations to attract new employees and to retain current staff (Shultz and Wang, 2011). Given the need for high engagement and commitment among a changing and increasingly diverse workforce, it is surprising that the majority of studies on Human Resource Management (HRM) have focused on the universalistic effects of so-called 'high performance work systems' on outcomes (Snape and Redman, 2010). More recently, however, there has been some debate as to whether HRM actually benefits all employees (Boxall and Macky, 2009; Combs et al., 2006). In addition, there is still a debate regarding how HRM relates to employee outcomes (Guest, 2011).

This study therefore introduces both a universalistic and a contingency approach to HRM (Delery and Doty, 1996) to explain (a) the specific processes through which universalistic HRM relates to employee outcomes among all employees, and (b) why some HRM practices are only related to outcomes for specific groups of employees. More specifically, this study investigates how universalistic developmental HRM relates to employee outcomes through rebalancing the psychological contract, while the relation between contingent accommodative HRM and employee outcomes is argued to be dependent upon employees' lifespan strategies in line with the Selection, Optimization, and Compensation (SOC) model (Baltes, 1997). ${ }^{[1]}$ Although the universalisticcontingency distinction in HRM has been investigated in macro-level studies (Delery and Doty, 1996; Purcell, 1999), only a few studies have used the contingency perspective in micro-research on HRM (see, for an exception, Kinnie et al., 2005) and no studies have integrated the universalistic-contingency distinction with the macro-micro relations between HRM and employee outcomes (Appelbaum et al., 2000; Guest, 1999). Hence, we present a multi-level framework which integrates the universalistic and contingency approach in the relations between macro-level HRM and micro-level outcomes.

The current study contributes to previous research on HRM in a number of ways. First, we argue and demonstrate that developmental HRM relates to higher outcomes among all workers by strengthening the relational contract while reducing the transactional contract (Rousseau, 1995). No study to date has ever revealed such a 'rebalancing' of the psychological contract between macro-level HR practices and micro-level individual outcomes. Furthermore, our study contributes to existing knowledge by introducing a contextualized perspective on the cross-level relations between macro-level HRM and individual-level employee outcomes, and thus by showing in the same study and framework that both a universalistic and a contingency perspective are valid. Yet the latter only applies to the relations of specific HR practices (namely accommodative HRM) with employee outcomes. In addition, by showing that accommodative HRM only relates to employee outcomes for people using SOC strategies, we provide a broader lens on the reasons behind such possible moderation effects, as the limited studies to date have tended to suggest that age would be a key moderator (e.g. Kooij et al., 2010). Finally, this paper adds to HR research by taking a multilevel perspective, thus bridging micro and macro research (Rousseau, 2011), and does so by examining the cross-level relations of unit-level HRM on psychological contracts and outcomes at the individual level. Figure 1 presents the conceptual model of this study. First, we will present the theoretical foundations, after which we will introduce the universalistic perspective on HRM and the contingency approach to HRM. 


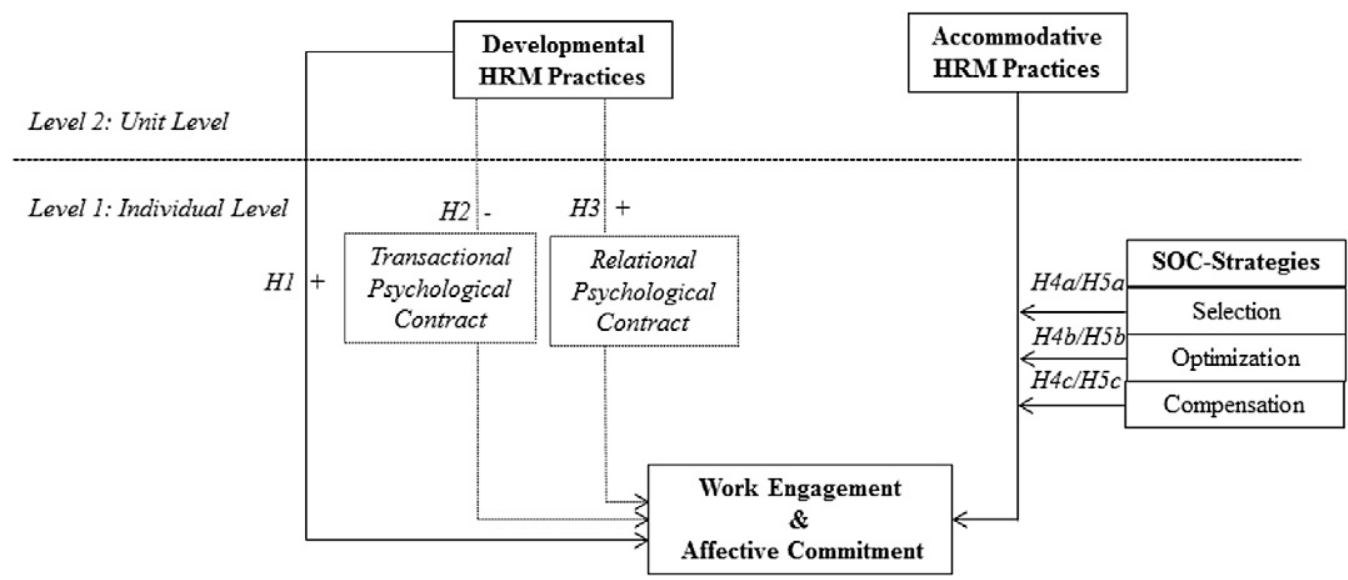

Figure 1. Multi-level research model of how unit-level HRM relates to individual-level SOC strategies, psychological contracts, and work engagement and affective commitment

\section{THEORY AND HYPOTHESES}

\section{Developmental HRM and Employee Outcomes: The Universalistic Perspective}

It is commonly argued that high performance HRM has a universal positive influence on employee outcomes (Jiang et al., 2012; Kehoe and Wright, 2013). While there is a debate about what precisely constitutes 'high performance HRM', some have characterized it as HRM aimed at enhancing employee outcomes rather than adjusting to organizational decline, such as downsizing and wage cutting (Paauwe, 2009). Yet, even though it has been suggested that psychological contracts mediate the relationship between HRM and employee outcomes (Paauwe, 2009), HRM research has not yet empirically tested this proposition. We thus expect psychological contract to mediate the relations between developmental HRM and engagement and commitment. To test these expectations thoroughly we will first replicate previous research that has shown that developmental HRM is related to higher engagement and commitment.

Previous research has shown that HRM influences organizational performance (Combs et al., 2006), and that this relation is mediated by employee perceptions and attitudes. Because many details on these mediators are still unclear, they are referred to as the 'black box' (Boxall and Macky, 2009; Paauwe, 2009). A prominent model that has been used in HRM (Allen et al., 2003; Edgar and Geare, 2005) is the AMO model (Appelbaum et al., 2000), which explains that employees will perform when they have the ability, motivation, and opportunity to do so. Developmental HRM, such as training and job enrichment, is particularly aimed at increasing the ability and motivation to perform by supporting the developmental needs of employees (Kuvaas, 2008; Zaleska and De Menezes, 2007).

Drawing from social exchange theory (Blau, 1964) it can be expected that this support will be reciprocated by employees through increased work engagement and affective commitment to the organization (Shore and Shore, 1995). Work engagement is defined 
as a positive, fulfilling, work-related state of mind characterized by vigour and dedication to the job (Schaufeli and Bakker, 2004); affective commitment is defined as a volitional psychological bond reflecting dedication to, and responsibility for, the organization (Klein et al., 2012). Specifically, Blau (1964) argues that people engage in a social exchange relationship when they voluntarily act in favour of another party, with the expectation that this favour is reciprocated in the future. Based on this notion, we likewise expect that when an organization offers development, there will be an expectation that employees will return this investment through higher engagement and commitment. This is in line with research demonstrating that work engagement mediates the relations between job resources (which result from HRM offered by the organization) and job performance (Christian et al., 2011), and thus forms a crucial link between that which the organization offers to the employees and how the employees perform. Hence, both engagement and commitment are important predictors of job performance (Harter et al., 2002; Kuvaas, 2008). Again in line with previous research, developmental HRM is therefore expected to relate to employee engagement and commitment. We propose the following hypotheses:

Hypothesis 1a: Unit-level developmental HRM is positively related to individual-level work engagement.

Hypothesis 1b: Unit-level developmental HRM is positively related to individual-level affective commitment.

\section{The Mediating Role of Psychological Contract for Developmental HRM}

Scholars have theorized that HRM serves as communication from the organization to employees (Guzzo and Noonan, 1994). This is in line with signalling theory (Casper and Harris, 2008), which postulates that since employees have imperfect information about the intentions of their organization, they use the availability of HRM practices as signals of the organization's intentions. It is thus argued that HRM leads to higher employee outcomes because it communicates the intentions of the employer, and hence influences the psychological contract employees have with their employer. In response, the employee will reciprocate the benevolence communicated by HRM (Guest and Conway, 2002; Guzzo and Noonan, 1994). However, the exact mediating role of the psychological contract in the relation between HRM and employee outcomes has not yet been examined. Psychological contracts refer to the employee's perceptions about the nature of the relationship with the organization (Rousseau, 1995). Yet, there are two classifications of psychological contracts, namely transactional and relational contracts (Rousseau, 1995; Rousseau and Parks, 1993). Transactional contracts are characterized by a shortterm, monetary scope, with little mutual involvement in the lives and activities of each other (Rousseau and Parks, 1993). The focus is purely materialistic, and employees only work to collect their salaries. Relational contracts, in contrast, are based on mutual agreement with exchanges of both monetary elements and socio-emotional elements. The focus of the relationship is long-term, open-ended, and primarily aimed at developing the employee (Rousseau and Parks, 1993). Because of this focus, relational 
contracts are theorized to be associated with more positive outcomes, whereas transactional contracts, because of the materialistic and short-term focus, are expected to be associated with more negative outcomes, including lower engagement and commitment (Raja et al., 2004; Rousseau, 1995).

Although no study has yet investigated the psychological contract as a mediator between HRM and employee outcomes, some research has been conducted on HRM in relation to social exchange relationships, which are more generic perceptions of employees about trust of the employee and investment of the employer (Shore et al., 2006; Song et al., 2009). However, while in social exchange relationships perceptions may be formed irrespective of the employer's involvement, the obligations constituting the psychological contract are grounded within promises from the employer. The foundation of psychological contracts is based upon perceived mutual agreement between employee and organization (Rousseau, 1995). Hence, the obligatory nature of the psychological contract is much stronger than the generic perceptions of social exchange. In line with this, meta-analytic work has shown that when psychological contracts are unfulfilled or breached, employees tend to respond strongly by reducing commitment and performance (Zhao et al., 2007).

Another critical distinction between the two is that unlike social exchange relationships (Shore et al., 2006; Song et al., 2009), psychological contracts include a timeframe; transactional contracts are aimed at short-term mutual obligations, while relational contracts focus on the long-term relationship between employee and organization. Because the aim of building a long-term relationship with the employee is a crucial part of why organizations invest in HRM (Kuvaas, 2008), it seems plausible that employees reciprocate with higher attitudes via changes in the psychological contract. Thus, even though management support relates to stronger perceptions among employees that they have a social exchange relationship (Shore et al., 2006; Song et al., 2009), it is important to investigate in more detail how HRM is related to the psychological contract, and subsequently to higher engagement and commitment.

Applying the distinction between the two types of psychological contracts to developmental HRM, we expect that developmental HRM reduces the transactional contract, because it indicates that the organization is not only interested in short-term gains, but is also concerned with long-term growth and developmental of employees. Millward and Hopkins (1998) suggest that reducing the transactional psychological contract is beneficial for the organization as employees with these contracts are short-term focused and not committed to the goals of their organization (Raja et al., 2004). At the same time we expect that because developmental HRM signals that there is a high likelihood of receiving long-term support and rewards from the organization, the relational contract is strengthened. Stated more from a social exchange perspective, we argue that by offering developmental HRM, organizations show that they are ready to uphold their end of the relationship, and that this induces employees to reciprocate via increasing their relational contract. In sum, we therefore propose the following hypotheses:

Hypothesis 2a: Transactional contract mediates the relationship between developmental HRM and employee engagement: developmental HRM negatively relates to transactional contract and transactional contract negatively relates to engagement. 
Hypothesis 2b: Transactional contract mediates the relationship between developmental HRM and affective commitment: developmental HRM negatively relates to transactional contract and transactional contract negatively relates to commitment.

Hypothesis 3a: Relational contract mediates the relationship between developmental HRM and employee engagement: developmental HRM positively relates to relational contract and relational contract positively relates to engagement.

Hypothesis 3b: Relational contract mediates the relationship between developmental HRM and affective commitment: developmental HRM positively relates to relational contract and relational contract positively relates to commitment.

\section{Accommodative HRM and Employee Outcomes: The Contingency Perspective}

Although researchers increasingly examine the dark side of high performance HRM (e.g. Jensen et al., in press), a more fundamental issue is the often overlooked possibility that not all HRM has a universal influence. Some researchers have advocated that a contingency approach is necessary to explain why HRM sometimes fails to achieve desired outcomes (Purcell, 1999). This contingency perspective has been primarily studied at the macro-, or organizational level, but Delery and Doty (1996) have argued that a contingency perspective on HRM also applies to micro-, or individual-level outcomes. For HRM to be effective, it must be consistent with other aspects of the organization or employees (Delery and Doty, 1996). Hence, the effectiveness of HRM is dependent upon macro factors, such as organizational strategy, but also on micro factors, such as employee preferences. In contrast to the universalistic benefits of developmental HRM, we expect the effects of accommodative HRM to be contingent upon the individual needs of employees.

Accommodative HRM is defined as those HRM practices aimed at meeting workers' needs for reduced workloads (Armstrong-Stassen and Ursel, 2009; Remery et al., 2003). Accommodative HRM has been inspired by disengagement theory (Adams, 1999; Cumming and Henry, 1961), which postulates that with increasing age, people gradually withdraw from their role in society when they prepare for retirement, as well as by SOC theory (Baltes et al., 1999), which postulates that employees who experience losses in their capabilities will use a number of strategies to adapt to their environment, namely selection, optimization, and compensation (Wiese et al., 2000, 2002). People select by narrowing their range of activities to fewer but more important or rewarding goals. For instance, employees may give up job responsibilities or involve others in their less central tasks because the overall workload becomes too high. Optimization refers to acquisition of, and investment in, means and abilities to achieve the goals people set in their work. For instance, people who perceive that their competencies are becoming obsolete may search for alternative strategies to maintain their performance. Finally, people compensate for losses through employing alternative means to maintain a desired level of functioning. For instance, people use pragmatic means (e.g. how they present themselves to others; Abraham and Hansson, 1995) to make up for losses they experience. More specifically, 
people act in ways that 'minimize the effects of developmental losses on the evaluation of their performance in the workplace' (Abraham and Hansson, 1995, p. 96). Previous research has shown that people who are successful in employing their SOC strategies obtain a more satisfactory level of performance at work (e.g. Wiese et al., 2000, 2002).

However, to successfully employ a desired SOC strategy it is necessary that the organization supports these strategies. As suggested in several studies (Ebner et al., 2006; Wiese et al., 2002), individuals employing different SOC strategies are likely to have different goals and needs. In particular, these studies reveal that individuals using SOC strategies are focused on prevention or regulation of losses and need to be accommodated to successfully cope with their ability losses. For this reason we expect accommodative HRM to be relevant to employees with SOC strategies, as it is contingent upon the specific needs of individuals experiencing losses. For example, both young and old workers alike who have a careerist-orientation (Rousseau, 1990) will not be particularly interested in workload reductions, while employees with specific work-life balancing issues will appreciate accommodative HRM regardless of their exact age. For employees not pursuing SOC strategies, accommodative HRM may even be associated with lower outcomes, because they signal disengagement from the workforce (Casper and Harris, 2008). Hence when organizations stress the possibility for employees to gradually withdraw, employees may feel the pressure to disengage rather than to fully invest in their work, and may thus become less engaged and committed (Bal et al., 2012). Consequently, we expect that the extent to which employees engage in SOC strategies affects the utility of accommodative HRM.

More specifically, social exchange theory proposes that employee reciprocation is related to the utility of HRM for employees (Blau, 1964). It can thus be expected that the availability of accommodative HRM is especially important for employees employing SOC strategies. Subsequently, when accommodative HRM is in place, these SOC strategists will become more highly engaged and committed (Abraham and Hansson, 1995). We expect that people aiming at regulating losses by selecting fewer activities to carry out, optimizing their performance on these activities, or compensating for losses by employing alternative means (Baltes, 1997), will be particularly responsive to the availability of accommodative HRM. Thus, we argue that accommodative HRM will be related to employee outcomes only for those employing SOC strategies. We propose the following hypotheses:

Hypothesis 4a: Selection moderates the relationship between accommodative HRM and work engagement, with positive relationships for employees high on selection.

Hypothesis 4b: Optimization moderates the relationship between accommodative HRM and work engagement, with positive relationships for employees high on optimization.

Hypothesis 4c: Compensation moderates the relationship between accommodative HRM and work engagement, with positive relationships for employees high on compensation. 
Hypothesis 5a: Selection moderates the relationship between accommodative HRM and affective commitment, with positive relationships for employees high on selection.

Hypothesis 5b: Optimization moderates the relationship between accommodative HRM and affective commitment, with positive relationships for employees high on optimization.

Hypothesis 5c: Compensation moderates the relationship between accommodative HRM and affective commitment, with positive relationships for employees high on compensation.

\section{METHODS}

\section{Participants and Procedure}

A healthcare organization in the Netherlands, providing daily care for mentally disabled people, took part in the study. This organization was chosen because in the Netherlands the healthcare sector faces both an aging workforce and many physically demanding jobs (Waldman et al., 2004). Therefore, healthcare organizations focus on both developing and accommodating employees (Veld et al., 2010). The organization consisted of 17 units, which until recently existed as separate operating organizations, and through mergers were incorporated into one organization. Therefore, (perceptions of) the availability of HRM differed significantly among the units (developmental HRM: $\mathrm{F}(1041,16)=2.95, \mathrm{p}<0.001$; accommodative HRM: $\mathrm{F}(1041,16)=2.85, \mathrm{p}<0.001)$. A total of 4500 employees were invited to take part in the study. Of these, 1058 employees filled out a digital or paper-and-pencil questionnaire (response rate 24 per cent). Mean unit size was 265 employees. Seventy-seven per cent of the participants were female, participants were on average 43 years of age $(\mathrm{SD}=10.88), 74$ per cent worked part-time (on average 25 hours a week), on average employees worked 14.68 years for the organization (or a predecessor of the organization), and 96 per cent had a permanent contract.

\section{Measures}

Availability of accommodative and developmental HR practices was measured by asking employees to indicate whether a number of HR practices were available in the organization. Possible answers were no (0), yes (1), or don't know. In line with previous work (Guest, 1999; Wright et al., 2001), we chose dichotomous indicators of HRM to ascertain as objectively as possible whether employees perceived that these practices were available. Through this objective approach, confounding issues are less likely to affect responses than more subjective Likert scales assessing the extent to which HR practices are available (Wright et al., 2001). Based on Remery et al. (2003), we included four accommodative practices: additional leave, exemption from overtime working, long career breaks, and partial retirement. We included five developmental practices: development on the job, internal promotion, job enrichment, lateral job movement or job rotation, and second career (i.e. retraining; Kuvaas, 2008; Zaleska and De Menezes, 2007). 
Individual-level scores were calculated through the total number of yes-responses. We focused on the unit-level because HR practices are communicated to employees by the unit managers. Prior organizational-level studies often assume no variation in HRM within an organization (Van De Voorde et al., 2010). However, in large organizations such as the current one, differences may exist between designed practices at the corporate level and the implemented practices across the units. Moreover, differences may exist in relevance of HRM for specific groups of employees (Lepak and Snell, 1999). Because managers differ in the extent to which they communicate about the availability of HRM (Arthur and Boyles, 2007), differences exist across the units in employee perceptions of HRM. Moreover, since the current organization resulted from the mergers of several separate organizations, which until recently existed as independent organizations with their own HR systems, we explicitly investigated whether there was variation across the units.

Scores of developmental and accommodative HR practices were aggregated to the unit level. Aggregation was appropriate since ICC1s of both developmental and accommodative HR practices were significant with a value of 0.03 , indicating that 3 per cent of the variance in individual scores depends on the unit (Klein et al., 2000). ICG1s are lower than recommended (LeBreton and Senter, 2008), yet this is not problematic when the sample is large, and when the other statistics fulfil the criteria (Klein et al., 2000; Van De Voorde et al., 2010). Moreover, even when 1 per cent of the variance can be attributed to unit membership, substantial higher level effects may exist (Bliese, 1998). Moreover, studies have reported similar ICG1 values (e.g. De Jong et al., 2005; Snape and Redman, 2010; Van De Voorde et al., 2010; Zhang et al., 2011). ICC2 was 0.66 for developmental HRM, and 0.65 for accommodative HRM. Values above 0.70 are considered as good and values above 0.50 as tolerable (Klein et al., 2000). Because between-unit variance scores ( $F$-tests) were significant and ICC2s were beyond the cut-off scores of 0.50 (LeBreton and Senter, 2008), we decided that there was enough evidence to aggregate the data for these two scales to the unit-level by taking the mean within each unit (Klein et al., 2000).

Psychological contract was measured with the scales from Millward and Hopkins (1998) and Raja et al. (2004). Transactional contract was measured with nine items, using a 5-point Likert-type scale ( $1=$ 'strongly disagree'; $5=$ 'strongly agree'). An example item is: 'I only carry out what is necessary to get the job done' (items are shown in Appendix II). Relational contract was also measured with nine items, an example being: 'I feel this company reciprocates the effort put in by its employees'. Raja et al. (2004) have previously demonstrated the convergent validity of this measure. We provide further construct validity for these measures in our confirmatory factor analyses.

SOC strategies were measured with adapted scales from Abraham and Hansson (1995). Answers were provided on a 6 -point scale ( $1=$ 'not at all'; $6=$ 'to a very great extent'). Selection $(\alpha=0.72)$ was measured with four items, with an example being: 'I now delegate low priority responsibilities to others'. Optimization $(\alpha=0.83)$ was measured with four items, of which an example item is: 'I now try to polish rusty skills and abilities so that my job performance won't suffer'. Finally, we measured compensation $(\alpha=0.83)$ with four items. An item is: 'I am now more careful about how I present myself to others at work'. 
Work engagement $(\alpha=0.93)$ was measured with seven items from the Utrecht Work Engagement Scale (UWES; Schaufeli and Bakker, 2004), indicating vigour, pride, and absorption in work $(1=$ 'never' to $6=$ 'every day'). An example item is: 'When I get up in the morning, I feel like going to work'. Affective commitment $(\alpha=0.86)$ was measured with eight items from Allen and Meyer (1990) using the same answer scale as psychological contract. An example item is: 'This organization has a great deal of personal meaning for me'.

\section{Analyses}

We conducted multiple tests for common method bias (Lindell and Whitney, 2001). First, we conducted a multilevel confirmatory factor analysis (CFA) for the item structure using Lisrel 8.72 (Jöreskog and Sörbom, 2008). Because CFA is not possible with dichotomous variables, we first calculated tetrachoric correlations based on the cross-tabulations between the perceived availability of all HR practices (Glöckner-Rist and Hoijtink, 2003; Uebersax, 2006). A measurement model was tested for the nine variables under study. We deleted all items with standardized loadings below 0.40 before we proceeded to constructing scale scores for the analyses, because otherwise constructs tend to be unreliable (Hu and Bentler, 1999). Conventional criteria use 0.40 as a cut-off for deciding whether or not to retain an indicator in the factor, and we ascertained that the factor loadings were all significant (Tabachnik and Fidell, 2007). Appendix I shows the fit statistics of the various models we tested, and Appendix II presents the factor loadings of the items. The nine-factor solution obtained good fit $\left(\chi^{2}=7635.95, \mathrm{p}<0.001\right.$, d.f. $=1172, \mathrm{RMSEA}=0.07, \mathrm{CFI}=0.92, \mathrm{IFI}=0.92)$, and fitted significantly better than alternative models. Subsequently, scale scores were calculated using the factor structure resulting from the CFA. In sum, the CFAs show that the nine-factor solution provides the best fit, and thus all variables represent empirically distinct constructs. Indicators load significantly on the latent variables, thus showing construct validity for the measures. Moreover, we calculated the Average Variance Extracted (AVE) scores (Fornell and Larcker, 1981), which are shown in Appendix II. All of the AVE scores were above the 0.50 cut-off scores, indicating convergent validity of our measures.

Furthermore, we used the marker variable approach (Lindell and Whitney, 2001) to determine the extent to which common method may be an issue in our data. Information reported by our respondents on a theoretically unrelated construct (i.e. self-efficacy; Chen et al., 2001) was used as a marker. Common method variance is more likely to be present if the level of significance of significant zero-order correlations for the variables in the study decrease when the marker variable is partialled out. Our analyses reveal that there were no statistically significant changes in the zero-order correlations after partialling out self-efficacy from the correlation matrix. These results thus indicate that selfreport issues are not a major concern. Moreover, previous research has shown that when common method variance exists, the chance to find significant results is deflated rather than inflated, and hence, when interactions are found, this can be perceived as strong evidence that such an effect exists (Siemsen et al., 2010).

The study provided data at the individual-level (level 1), which are nested in the higher unit-level (level 2). Because these observations are interdependent, multilevel analysis is required (Hox, 2002), and MLWin 2.20 was used (Rasbash et al., 2000). The 
independent variables were grand-mean centred, and we used random intercept modelling (Hox, 2002). A staged approach was used to build equations. Engagement and commitment may be influenced by demographic variables such as gender, age, education, type of contract (part-time vs. full-time), and tenure, and hence we controlled for these in our analyses. First, an intercept-only model was created, after which demographic variables and independent variables were added. Mediation was tested according to the recommendations of Mathieu and Taylor (2007). Cross-level interactions were added to the equations in separate models. We included non-hypothesized interactions as well (e.g. SOC strategies moderating the relations of developmental HRM), in order to rule out alternative explanations. Significant interactions were plotted with one standard deviation below and above the mean (Aiken and West, 1991).

\section{RESULTS}

Table I presents the means and correlations among the variables. Hypotheses $1 \mathrm{a}$ and $1 \mathrm{~b}$ predicted positive relations between developmental HRM and employee outcomes. Table II shows the multilevel regression analyses of work engagement and affective commitment on HRM and the two psychological contract types. First, the control variables were added to the equations. To test the hypotheses, both of the level 2 predictors were added. Developmental HRM was positively related to work engagement $(\gamma=0.181, \mathrm{p}<0.05$; Model 1$)$ and to affective commitment $(\gamma=0.223, \mathrm{p}<0.01$; Model 3 ), irrespective of the simultaneously added accommodative HRM (which was nonsignificant (NS); work engagement: $\gamma=-0.181$, NS; affective commitment: $\gamma=0.124$, NS). Therefore, Hypotheses $1 \mathrm{a}$ and $1 \mathrm{~b}$ were supported.

Hypotheses 2 and 3 predicted that the two psychological contract types mediate the relationship between developmental HRM and employee outcomes. Table II shows the results of the multilevel analyses of the psychological contract on HRM, and of employee outcomes on HRM and psychological contract. Developmental HRM was negatively related to transactional contract $(\gamma=-0.137, \mathrm{p}<0.01$; Model 6) and positively related to relational contract $(\gamma=0.270, \mathrm{p}<0.001$; Model 8). The relationship between developmental HRM and work engagement was fully mediated, as the relationship became non-significant after adding the psychological contract variables $(\gamma=-0.004$, NS; from $\gamma=0.181, \mathrm{p}<0.05$; Model 2 vs. Model 1). The relation between developmental HRM and commitment was also fully mediated by transactional and relational contract, as the relationship became non-significant $(\gamma=0.081$, NS; from $\gamma=0.223$, p $<0.01$; Model 4 vs. Model 3) after inclusion of transactional and relational contract. At the same time, the relationships between transactional and relational contracts and work engagement $(\gamma=-0.470, \mathrm{p}<0.001$ and $\gamma=0.415, \mathrm{p}<0.001$; Model 2$)$, and with affective commitment, were significant $(\gamma=-0.140, \mathrm{p}<0.001$ and $\gamma=0.459, \mathrm{p}<0.001$; Model 4). Sobel tests were also significant for work engagement for both types of psychological contract (Transactional: $\mathrm{z}=2.82, \mathrm{p}<0.01$; Relational: $\mathrm{z}=3.021, \mathrm{p}<0.01$ ), as well as for affective commitment (Transactional: $\mathrm{z}=2.39, \mathrm{p}<0.05$; Relational: $\mathrm{z}=3.12, \mathrm{p}<0.01$ ). Hypotheses 2 and 3 were thus fully supported.

Hypothesis 4 predicted interaction effects of SOG strategies in the relationship between accommodative HRM and engagement. Table III shows the results for engagement. 


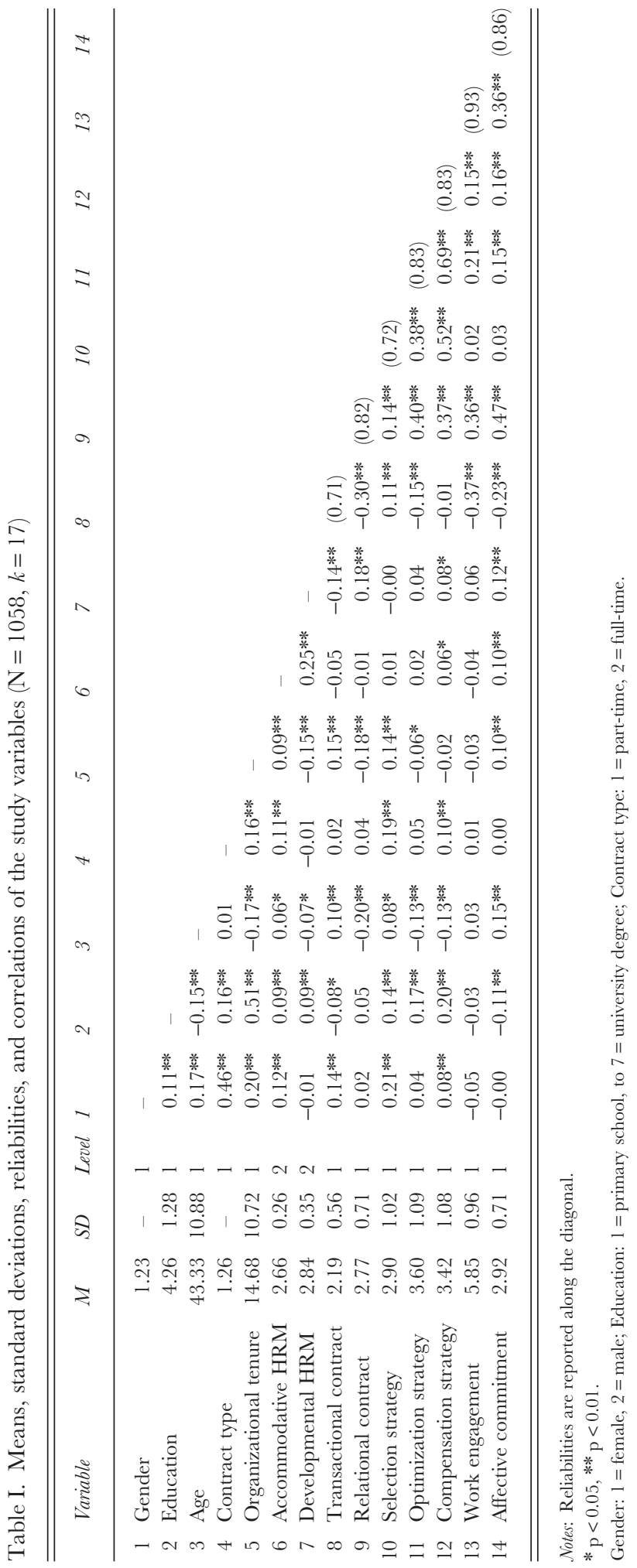


HRM, SOC, and Psychological Contract

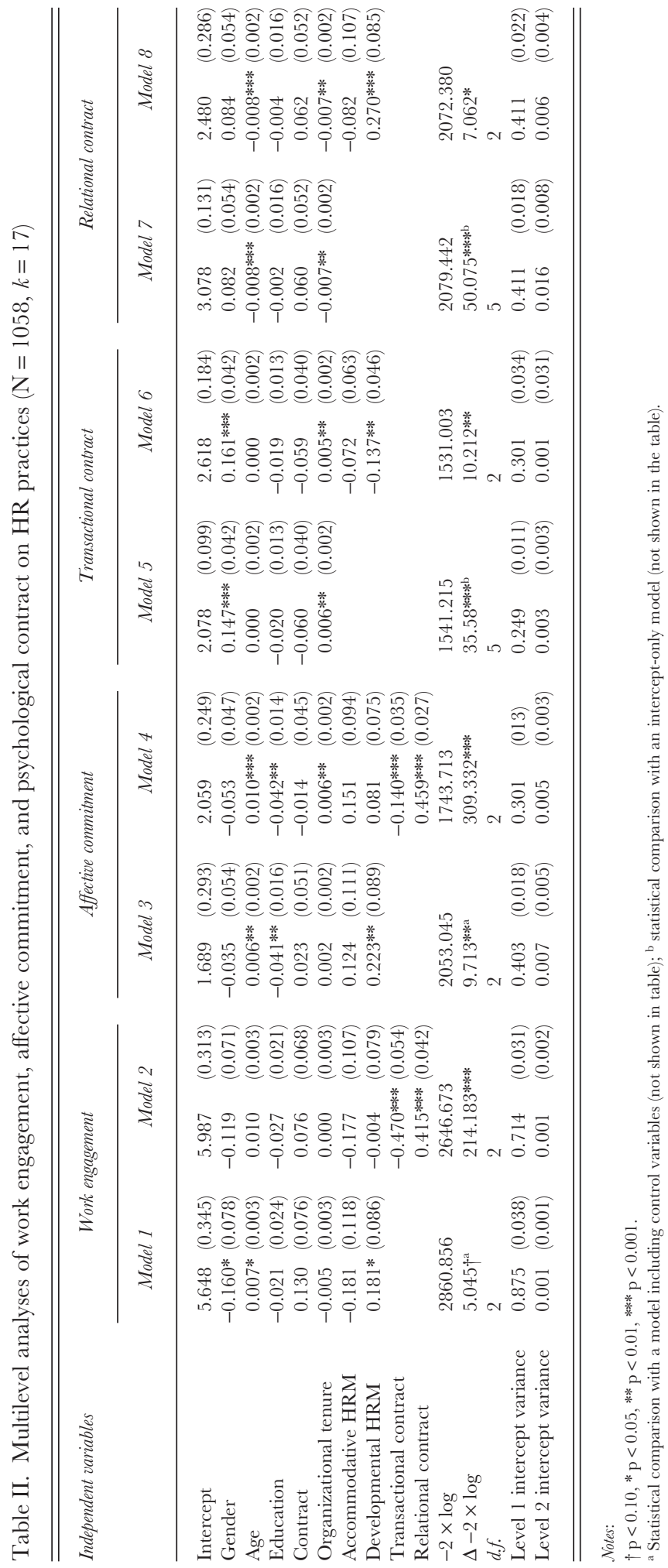

(C) 2013 John Wiley \& Sons Ltd and Society for the Advancement of Management Studies 
P. M. Bal et al.

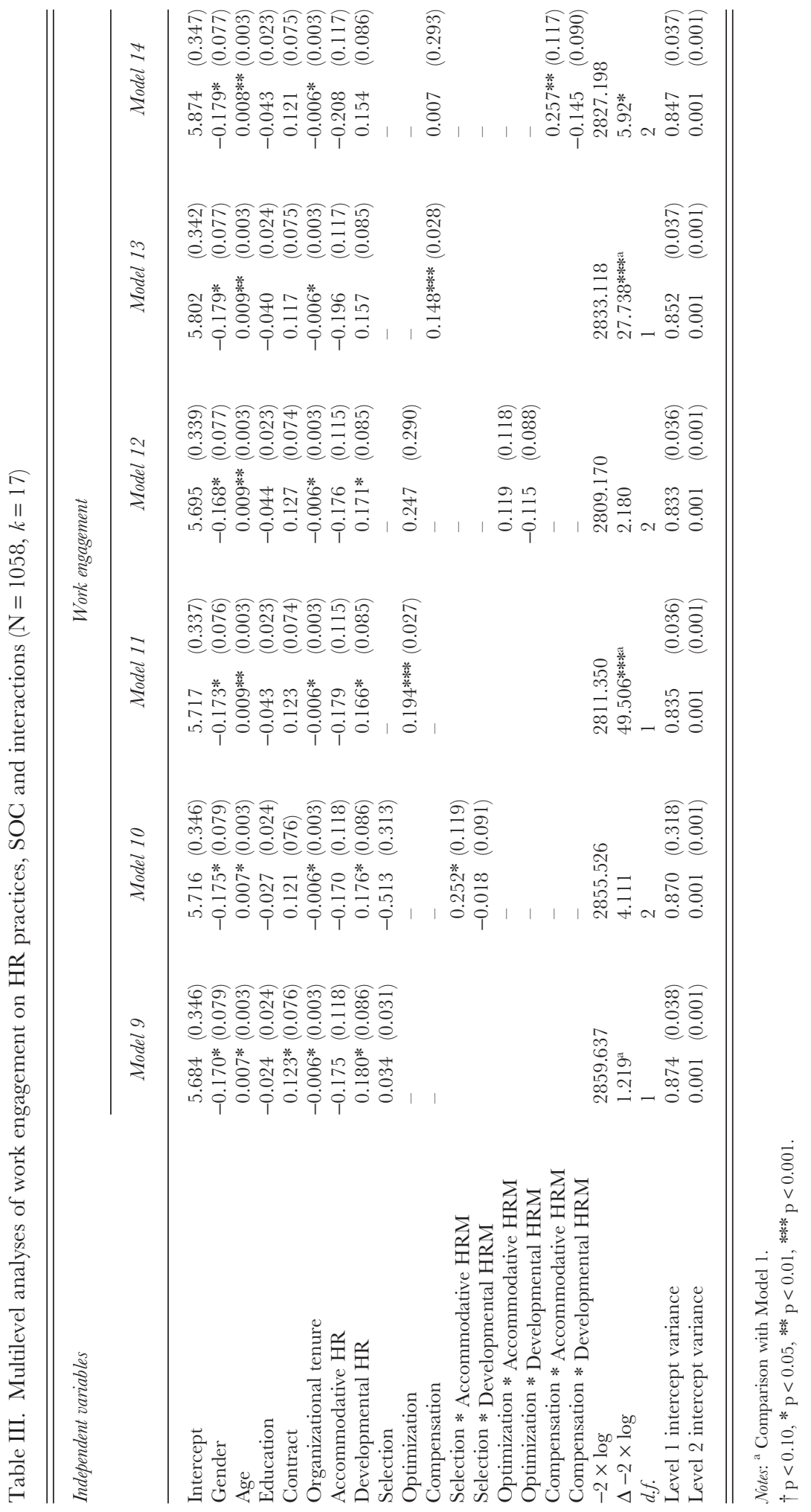




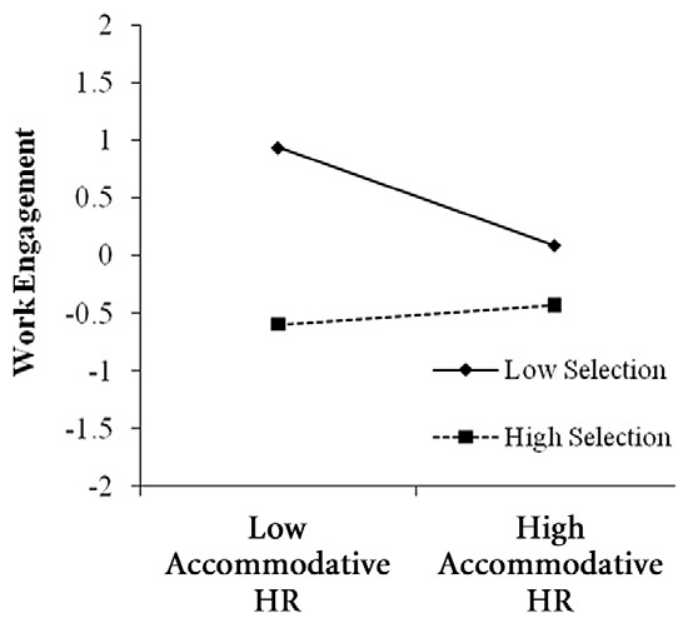

Figure 2. The interaction between unit-level accommodative HRM and individual-level selection strategies in relation to employee's work engagement

Supporting Hypothesis 4a, selection interacted significantly with accommodative HRM in relation to work engagement $(\gamma=0.252, \mathrm{p}<0.05$; Model 10). Figure 2 shows the interaction effect. The slope of accommodative HRM was negative for people low in selection (1SD below the mean; $\gamma=-0.422, \mathrm{p}<0.01$ ), while the relationship was non-significant for people with high selection (1SD above the mean; $\gamma=0.082$, NS). In contrast to Hypothesis $4 \mathrm{~b}$, optimization did not moderate the relationship between accommodative HRM and engagement ( $\gamma=0.119$, NS; Model 12). Supporting Hypothesis 4c, compensation moderated the cross-level relationship between accommodative HRM and engagement positively $(\gamma=0.257, \mathrm{p}<0.01$; Model 14). Figure 3 shows that for employees with low compensation, accommodative HRM was negatively related to work engagement $(\gamma=-0.465, \mathrm{p}<0.01)$, while the relationship was non-significant for employees with high compensation $(\gamma=0.049$, NS). We also tested the alternative hypothesis that SOC moderated the relationship between developmental HRM and work engagement. Neither selection $(\gamma=-0.018$, NS), optimization $(\gamma=-0.115$, NS), nor compensation $(\gamma=-0.145$, NS) moderated the relationship between developmental HR practices and engagement. In sum, Hypotheses $4 \mathrm{a}$ and $4 \mathrm{c}$ were supported.

Hypothesis 5 predicted interactions of SOC with accommodative HRM in relation to commitment. Table IV shows the results for commitment. In support of Hypothesis 5a, selection interacted with accommodative HRM in relation to commitment $(\gamma=0.186$, $\mathrm{p}<0.05$; Model 15). Figure 4 shows that the slope of accommodative HRM for people low in selection was not significant $(\gamma=-0.057, \mathrm{NS})$, whereas the relationship was positive for people with high selection $(\gamma=0.315, \mathrm{p}<0.05)$. Further, Hypothesis $5 \mathrm{~b}$ is rejected since optimization did not moderate the relationship between accommodative HRM and commitment $(\gamma=0.087$, NS; Model 18). Finally, supporting Hypothesis 5c, compensation moderated the relationship between accommodative HRM and commitment positively $(\gamma=0.213, \mathrm{p}<0.01$; Model 20). Figure 5 shows the interaction pattern. For employees with low compensation, accommodative HRM was not significantly 


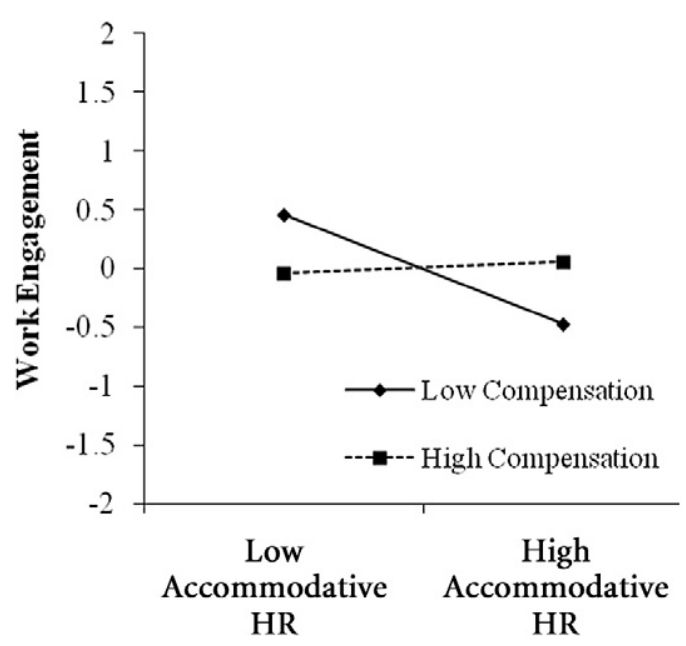

Figure 3. The interaction between unit-level accommodative HRM and individual-level compensation strategies in relation to employee's work engagement

related to affective commitment $(\gamma=-0.123, \mathrm{NS})$, whereas the relationship was positive for employees with high compensation $(\gamma=0.303, \mathrm{p}<0.05)$. We also found that selection $(\gamma=-0.045, \mathrm{NS})$, optimization $(\gamma=0.016, \mathrm{NS})$, and compensation $(\gamma=-0.042, \mathrm{NS}) \mathrm{did}$ not moderate the relationship between developmental HRM and commitment.

\section{DISGUSSION}

Due to the aging workforce (e.g. Shultz and Wang, 2011), organizations are nowadays increasingly focused on retaining their (older) employees. The challenge for designing HRM systems is not only to entice employees to stay in the company, but also to make employees engaged in their work and committed to their organization, and thus create productive employees (Guthrie, 2001). Within this context of a changing workforce, and by integrating the universalistic as well as the contingency perspective on HRM (Delery and Doty, 1996), this study investigated the effects of two different types of unit-level HR practices on two individual-level employee outcomes. Our results showed that developmental HRM universally relates to a more relational contract and thus to higher employee engagement and commitment. Conversely, the more developmental HRM is available, the less employees perceive their psychological contract as transactional, and this is also associated with more engagement and commitment. Hence, our results show that developmental HRM rebalances the psychological contract, such that employees perceive it as less transactional and more relational. Even though it has been suggested that psychological contracts are not necessarily contractual (Guest, 1998), they are important to consider as they capture the basic perceptions of employees regarding the mutual obligations between them and their organizations (Rousseau, 1995) and affect important outcomes.

While developmental HRM 'rebalances' the psychological contract into a more benevolent one and thereby relates to higher engagement and commitment, the 
HRM, SOC, and Psychological Contract

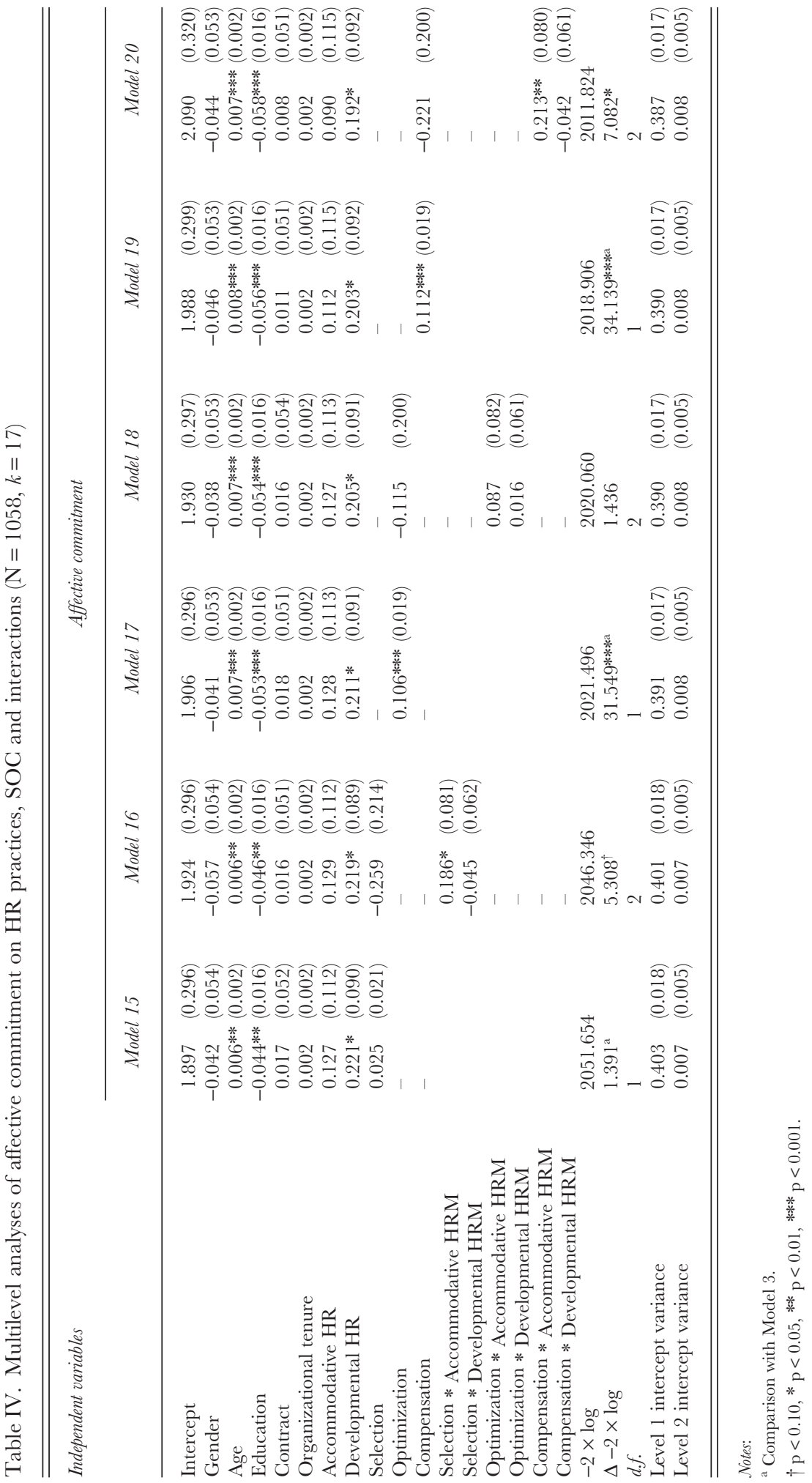

(C) 2013 John Wiley \& Sons Ltd and Society for the Advancement of Management Studies 


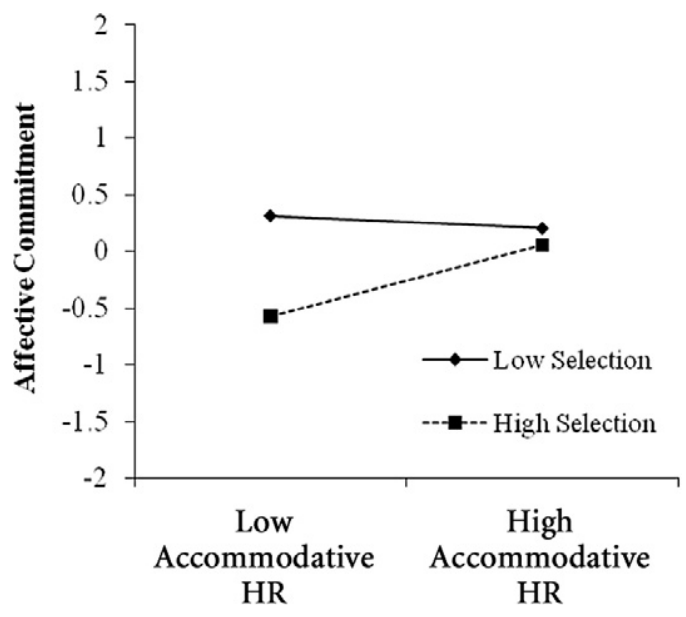

Figure 4. The interaction between unit-level accommodative HRM and individual-level selection strategies in relation to employee's affective commitment

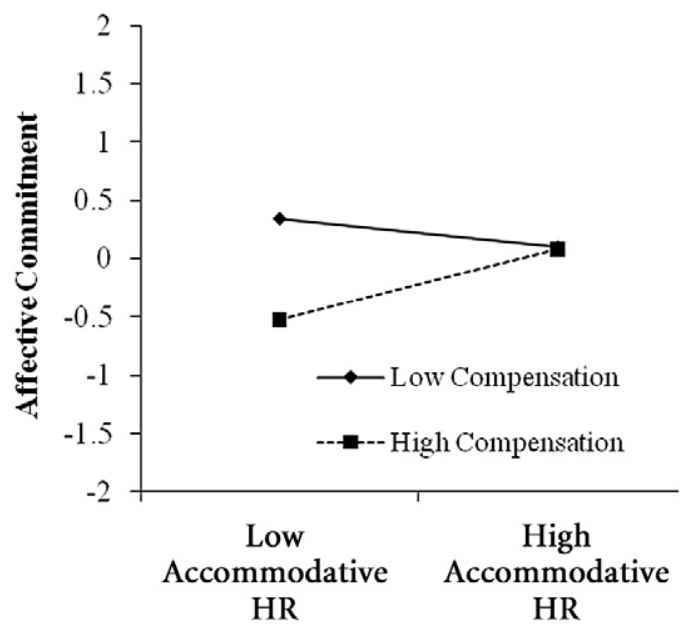

Figure 5. The interaction between unit-level accommodative HRM and individual-level compensation strategies in relation to employee's affective commitment

relationship between contingent accommodative HRM and employee outcomes is (as expected) less straightforward. More specifically, drawing from the SOG model (Baltes et al., 1999) we argued, and subsequently found, that commitment is enhanced when high selection and compensation employees have the opportunity to use accommodative HRM. We also found that engagement is decreased when employees with low selection and compensation strategies have the opportunity to use accommodative HRM. The latter result can be explained by taking into account that low selection and compensation employees are those employees who are healthy and more easily stay active in their work. When organizations stimulate the use of accommodative practices, they may send out 
the signal that employees should disengage rather than stay active at work (Adams, 1999; Bal et al., 2012). Hence, our findings suggest that when employees do not need these practices, availability may become a pressure to disengage, instead of staying active, and consequently employee engagement decreases.

We found no moderating effects of the optimization strategy on the relationship between accommodative HRM and employee outcomes. Since optimization is more focused on maximizing available resources, a possible explanation is that those employees focusing on optimizing their skills will already profit from the availability of developmental practices and hence accommodative practices do not additionally contribute to higher employee outcomes (Armstrong-Stassen and Ursel, 2009). Another explanation is that accommodative HRM is not useful for employees pursuing an optimization strategy, because they might seek other ways to optimize their resources. Therefore, one option would be to expand the measure of optimization such that it also captures other forms, such as optimization outside of the workplace (Wiese et al., 2000, 2002). Moreover, it could be that optimizers search for other HR practices that fulfil their needs, such as career counselling or mentoring. As such, the accommodative HRM scale could also be further developed.

\section{Contributions}

Our study contributes to knowledge in the following ways. We have integrated the debates on universalistic versus contingent HRM (Delery and Doty, 1996; Purcell, 1999) with the macro-micro influence of HRM on employee outcomes. We extend previous research that found that universalistic developmental HRM relates to higher individuallevel outcomes (e.g. Kehoe and Wright, 2013; Kuvaas, 2008) by studying the mediating process of the psychological contract. One of our key contributions is that we demonstrated that it is through the reshaping of the psychological contract that employees become more committed and engaged in response to the availability of developmental HRM. Developmental HRM relates to employees having a more relational and less transactional contract, and this is associated with higher engagement and commitment. Hence, we provide more insight into that which has been often referred to as the 'black box' in HRM research (Paauwe, 2009), namely how the perceptions of employees regarding HRM determine their investments in their relationship with the organization and ultimately also affect their attitudes towards work and the organization. We showed that this can be understood through the psychological contract (Paauwe, 2009), and so emphasized and explained in more detail the role of the employee in the equation between HRM and employee outcomes.

Second, our study is the first to show that, consistent with SOC theory (Baltes et al., 1999), accommodative HRM decreases engagement for low selection and compensation employees while it enhances commitment only for people endorsing selection and compensation strategies. These findings suggest that accommodative HRM may send out adverse signals to employees who do not need it, and that may cause them to feel pressure to disengage rather than to remain active members of the organization (Bal et al., 2012). Our study contributes to contemporary knowledge by showing that it is accommodative HRM which may help employees to stay committed while they face 
losses in their capabilities and focus on the SOC strategies of selection and compensation to cope with these losses. In additional, our results underline the need to not focus on broad proxies such as age, as the more specific strategies associated with losses due to age are more informative and can be used to build more specific interventions (Kooij et al., 2010).

It is also important to put our results and contributions in the organizational context of the study. First, in the current organization, perceptions of availability of HRM varied between 26 and 35 per cent, while we discovered from interviews with managers, which were conducted after the surveys, that a smaller percentage of employees actually used these HR practices. In line with signalling theory (Casper and Harris, 2008), which postulates that when employees are aware of the existence of an HRM practice they interpret this as a positive signal from the organization, availability was found to enhance employee outcomes. Yet, organizations might also focus on enhancing the actual use of HR practices to ensure that employees also actually develop themselves. Moreover, the context of healthcare organization meant that many female employees were employed and that most employees worked part-time. Working part-time is more common in healthcare (Veld et al., 2010) and can be regarded as an HR practice that accommodates those employees who are no longer able to conduct their work full-time. Finally, older workers are generally entitled to certain accommodative practices, such as additional leave. It is important to realize that this may create a situation of inequity and it is therefore important for managers to ensure fair treatment of employees. This could, for instance, be done through individual negotiations with employees about fair distribution of resources across the units (Rousseau, 2005).

\section{Limitations and Suggestions for Further Research}

One of the limitations of this study was the cross-sectional nature; the variables were measured at a single point in time and therefore causal inferences cannot be made. For instance, it could be argued that more highly engaged and committed employees perceive higher availability of HRM in the organization. Such a seemingly 'counter-intuitive' causal relationship could be created because employers may actually offer engaged and committed employees more HRM. Alternatively, these employees may have a more positive view of their work and will, therefore, perceive HRM more positively. Although our measure of HRM experienced by employees used a 'yes/no' scale in order to reflect more objectively the availability of $\mathrm{HR}$ practices, compared to more subjective Likert-scales which assess the extent to which HRM is available (Wright et al., 2001), it is important that longitudinal research is conducted to disentangle reversed causal processes. Moreover, investigation of the actual use of HR practices beyond perceptions by employees would further enhance the understanding of the effects of HRM at the workplace.

Second, we relied upon employees' perceptions of the availability of HRM. Even though many studies have based their assessment of HRM on employees (Kehoe and Wright, 2013; Kuvaas, 2008), it is important to compare the views from the employer with those of the employees (Guest and Conway, 2002). This would also provide more insight into the communication process of how HRM is offered and implemented throughout the organization (Guest, 2011). 
Furthermore, caution should be taken when generalizing our results to a broader population, as participants in our study were from the healthcare sector. In this sector both psychological and physical labour form important aspects of the job. Therefore, employees in the healthcare sector may use more selection and compensation-strategies in their work, because of the impact of declining physical capabilities (e.g. not being able to wash patients or to carry patients out of bed). As such, it is necessary to investigate how HRM and SOC strategies may help employees to stay committed and productive across a wider range of sectors. While commitment-focused HR systems tend to be currently used primarily within organizations with relatively higher proportions of knowledge workers (Lepak and Snell, 1999), the need for all organizations to increase employee engagement and commitment will grow now that the population is aging and the workforce is shrinking (Shultz and Wang, 2011).

Future studies should also pay attention to the possibility that HRM is differentially applied to employees by organizations. For instance, it has been suggested that when HR practices are primarily targeted at core employees rather than temporary workers, developmental and accommodative HRM may be less beneficial for these contingent workers (Lepak and Snell, 1999). However, our study indicates that, regardless of type of contract, providing employees with opportunities for development will enhance their engagement and commitment, while SOC strategies (and not type of contract) moderate the relation between accommodative HRM and employee outcomes. Explicitly investigating this 'targeting' of HRM to specific employees might thus be a worthwhile endeavour for future research.

Another critique might be that our study was conducted in a single organization, consisting of multiple units. However, we found sufficient similarity within, and variation across, the units in the perceptions of HRM to conclude that our choice of research setting was appropriate. Yet, it is likely that perceptions of HRM will vary to an even greater extent among units of different organizations, especially if these organizations operate in different sectors. The downside is that research of such heterogeneous samples has its own particular weaknesses, such as potentially introducing confounding biases. We therefore deemed it appropriate to start with this line of research by first focusing on multiple units of a single organization to avoid such potential confounding effects. However, now that the basic relationships have been indicated, it is important to examine multiple organizations to further integrate lifespan psychological theories, HR research, and employee outcomes.

Finally, we have focused on HRM that aims at enhancing employee outcomes, such as engagement and commitment. However, in the current crisis, many organizations are dealing with decline, and focus on downsizing, layoffs, and wage-cutting. Future research might therefore also investigate 'negative' HRM to show how organizations that employ these types of employee adverse practices can maintain employee engagement and commitment.

\section{Implications for Practice}

The current study has a number of practical implications. Our findings show that it is imperative that organizations distinguish between various types of HRM (Delery and 
Doty, 1996; Purcell, 1999), as both universalistic and contingent HRM relate to employee outcomes, but via different mechanisms. However, we also advise organizations to be cautious of promoting accommodative practices too forcefully, since these may also decrease employee engagement. Enhancing engagement and commitment is important for organizations as previous research has shown that they are beneficial for performance and retention of employees (Harrison et al., 2006) and our primary advice is therefore to provide developmental HRM to all employees. Our results show that these investments in developing employees pay off in terms of higher engagement and commitment because they are related to a stronger relational, and less transactional, relationship between employee and employer. However, organizations should also be aware that not all HRM leads to higher employee engagement and commitment, and hence, the cost-effectiveness of HRM is not universal (Kaufman and Miller, 2011). Therefore, cost-effectiveness is another aspect which organizations will have to take into account when implementing HRM.

Accommodative practices, for instance, should only be targeted at specific employees within the organization, as we found that these practices are only beneficial for employees struggling with the demands they face in their work lives. Employees experiencing losses, such as declining health, will be focused on finding a balance between the resources that are available to them and the demands they face at their work. Therefore, they employ strategies that limit the number of goals in their work, and that allow them to use alternative means to reach their work goals. Accommodative HRM, including reduced workload and exemption from irregular working hours, will help these employees to find this balance. However, since these accommodative practices may also be costly and have adverse effects on engagement (Remery et al., 2003), organizations should take up an individual approach when they offer these practices to employees. In line with previous research on idiosyncratic deals (Bal et al., 2012; Rousseau, 2005), we therefore argue that organizations, and more specifically managers, should negotiate individual agreements with employees that fit with the employee's SOG strategies. Our results indicate that, in line with well-established social exchange principles, managers who offer such individualized agreements to specific employees can expect to get in return higher employee engagement and commitment, and thus also higher loyalty, performance, and retention.

An important precondition for success of these agreements is most likely co-worker acceptance of the agreement (Lai et al., 2009). For instance, a manager in healthcare can negotiate with an employee who has parental care responsibilities that he/she works fewer hours during the working week, but is available to work more in the weekends, so that employees with dependent children do not have to work as often in the weekends. In this case, both employees have a specific I-deal, but all parties would be satisfied with these individualized agreements.

\section{GONGLUSION}

The current study has shown that, in line with a universalistic approach to HRM, developmental HRM universally relates to employee outcomes by creating a less transactional and a more relational psychological contract. However, in line with a 
contingency approach to HRM, this study also showed that accommodative HRM does not have a universal effect, as it only relates to engagement and commitment when it is in line with employee needs. More specifically, employees focused on selection of goals or compensation of losses benefit from the availability of accommodative HRM, whilst those who do not have such strategies might actually become more disengaged. Hence, our research shows that in light of the changing workforce it is important to distinguish clearly between universalistic and contingent HRM in order to effectively increase employee engagement and commitment.

\section{AGKNOWLEDGMENT}

The authors thank David Guest for his comments on an earlier draft of the article.

\section{NOTE}

[1] This universalistic-contingency distinction is similar to the distinction between best practices and best-fit practices (Boxall and Purcell, 2011; Purcell, 1999). Both universalistic and best-practices perspectives assume that some HR practices benefit organizations and employees in every situation, and that all organizations should adopt these practices. Moreover, both contingency and best-fit practices assume that some HR practices are only beneficial in certain circumstances and only benefit those in need for these practices.

\section{APPENDIX I: RESULTS OF SGALE ANALYSES USING MULTILEVEL FACTOR ANALYSES}

\begin{tabular}{llrllllll}
\hline \hline Model & CFA & \multicolumn{1}{c}{$\chi^{2}$} & $d f$ & RMSEA & CFI & IFI & $\Delta d f$ & $\Delta \chi^{2}$ \\
\hline Baseline & 9 factors & $7,635.95^{* * * *}$ & 1,172 & 0.070 & 0.92 & 0.92 & - & Baseline model \\
Alt. 1 & 8 factor HR & $8,130.35^{* * *}$ & 1,180 & 0.073 & 0.91 & 0.91 & 8 & $494.40^{* * * *}$ \\
Alt. 2 & 8 factor PC & $8,696.65^{* * *}$ & 1,180 & 0.076 & 0.91 & 0.91 & 8 & $1,060.70^{* * *}$ \\
Alt. 3 & 8 factor EO & $10,202.45^{* * *}$ & 1,180 & 0.083 & 0.89 & 0.89 & 8 & $2,566.50^{* * *}$ \\
Alt. 4 & 8 factor RPG-AC & $10,107.93^{* * *}$ & 1,180 & 0.082 & 0.90 & 0.90 & 8 & $2,471.98^{* * *}$ \\
Alt. 5 & 8 factor OC & $8,193.53^{* * *}$ & 1,180 & 0.073 & 0.91 & 0.91 & 8 & $557.58^{* * *}$ \\
Alt. 6 & 7 factor SOC & $8,988.11^{* * *}$ & 1,187 & 0.077 & 0.91 & 0.91 & 15 & $1,352.16^{* * *}$ \\
Alt. 7 & 1 factor & $29,750.33^{* * *}$ & 1,208 & 0.150 & 0.77 & 0.77 & 36 & $22,114.38^{* * *}$ \\
\hline \hline
\end{tabular}

Notes: Baseline model refer to a model with accommodative HRM, developmental HRM, transactional contract, relational contract, selection, optimization, compensation, work engagement and commitment; Alt.1 refers to HRM combined in one factor; Alt. 2 refers to one psychological contract factor; Alt. 3 refers to work engagement and affective commitment combined in one factor; Alt. 4 refers to relational PC and affective commitment in one factor; Alt. 5 refers to optimization and compensation as one factor; Alt. 6 refers to selection, optimization, and compensation combined in one factor; Alt. 7 refers to all items together. CFA = Confirmatory Factor Analysis; RMSEA = Root Mean Square Error of Approximation; CFI = Comparative Fit Index; IFI = Incremental Fit Index. 


\section{APPENDIX II: STANDARDIZED FAGTOR LOADINGS OF THE ITEMS UNDER STUDY (GONFIRMATORY FAGTOR ANALYSIS)}

\begin{tabular}{llllllllll}
\multicolumn{10}{c}{ Factor } \\
\hline 1 & 2 & 3 & 4 & 5 & 6 & 7 & 8 & 9
\end{tabular}

$\begin{array}{ll}\text { Accommodative HRM practices } & \\ \text { 1 Additional leave } & 0.47 \\ \text { 2 Exemption from overtime work } & 0.7 \\ \text { 3 Long career breaks } & 0.6 \\ \text { 4 Partial retirement } & 0.66 \\ \text { Developmental HRM practices } & \end{array}$

$\begin{array}{ll}\text { 1 Development on the job } & 0.65 \\ \text { 2 Internal promotion } & 0.67 \\ \text { 3 Job enrichment } & 0.60 \\ \text { 4 Lateral job movement or job rotation } & 0.76 \\ \text { 5 Second career (i.e. retraining) } & 0.66\end{array}$

Transactional contract $(\alpha=0.71)$

1 I work only the hours set out in my contract and no 0.47 more

2 My commitment to this organization is defined by my contract

3 I prefer to work a strictly defined set of working hours

4 I only carry out what is necessary to get the job done

5 I work to achieve the purely short-term goals of my job

6 It is important to be flexible and to work irregular hours if necessary $(\mathbf{R})$

7 My loyalty to the organization is contract specific

8 I do not identify with the organization's goals

9 My job means more to me than just a means of paying the bills $(R)$

Relational contract $(\alpha=\mathbf{0 . 8 2})$

$1 \mathrm{I}$ expect to grow in this organization

2 I have a reasonable chance of promotion if I work hard

3 To me working for this organization is like being a member of a family

4 The organization develops/rewards employees who work hard and exert themselves

5 I expect to gain promotion in this company with length of service and effort to achieve goals

6 I feel this company reciprocates the effort put in by its employees

7 I am motivated to contribute $100 \%$ to this company in return for future employment benefits

8 I feel part of a team in this organization

$9 \mathrm{My}$ career path in the organization is clearly mapped out

Selection $(\alpha=0.72)$

$1 \mathrm{I}$ am now more likely to involve others in my less central tasks

2 I now delegate low priority responsibilities to others

3 I now try to reduce my overall workload

4 I now try not to waste time on less important job responsibilities 
Factor

\begin{tabular}{llllllllll}
\hline 1 & 2 & 3 & 4 & 5 & 6 & 7 & 8 & 9
\end{tabular}

Optimization $(\alpha=\mathbf{0 . 8 3})$

1 I now try to polish rusty skills and abilities so that 0.54 my job performance won't suffer

2 I now focus substantial efforts on maintaining and maximizing job skills and abilities

3 I now make special efforts to maintain skills and abilities that are related to my job

4 I now take any opportunity to retain or polish rusty skills

\section{Compensation $(\alpha=\mathbf{0 . 8 3})$}

1 I now try to let others know about my special knowledge and skills

2 I am now more careful about how I present myself to others at work

3 I now try to make my accomplishments visible to my boss

4 I now take advantage of opportunities to demonstrate my special skills and abilities to coworkers

\section{Work engagement $(\alpha=\mathbf{0 . 9 3})$}

1 At my work, I feel bursting with energy $\quad 0.78$

2 At my job, I feel strong and vigorous $\quad 0.76$

$\begin{array}{lr}3 \text { I am enthusiastic about my job } & 0.93\end{array}$

4 My job inspires me $\quad 0.90$

5 When I get up in the morning, I feel like going to 0.82 work

6 I am proud on the work that I do $\quad 0.79$

7 I receive energy from my work $\quad 0.87$

Affective commitment $(\alpha=\mathbf{0 . 8 6})$

1 I enjoy discussing my organization with people outside it

2 This organization has a great deal of personal meaning for me

3 I feel 'emotionally attached' to this organization

4 I would be very happy to spend the rest of my career with this organization

5 I feel a strong sense of belonging to $m y$ organization

6 I feel like 'part of the family' at my organization

7 I really feel as if this organization's problems are my own

8 I think that I could easily become as attached to another organization as I am to this one $(R)$

Note: Items in italics were deleted from further analyses because of standardized coefficients below 0.40 .

\section{REFERENGES}

Abraham, J. D. and Hansson, R. O. (1995). 'Successful aging at work: an applied study of selection optimization and compensation through impression management'. Fournal of Gerontology. Series B Psychological Sciences and Social Sciences, 50B, 94-103.

Adams, G. A. (1999). 'Career-related variables and planned retirement age: an extension of Beehr's model'. Fournal of Vocational Behavior, 55, 221-35. 
Aiken, L. S. and West, S. G. (1991). Multiple Regression: Testing and Interpreting Interactions. San Francisco, CA: Sage Publications.

Allen, D. G., Shore, L. M. and Griffeth, R. W. (2003). 'The role of perceived organizational support and supportive human resource practices in the turnover process'. Fournal of Management, 29, 99-118.

Allen, N. J. and Meyer, J. P. (1990). 'The measurement and antecedents of affective continuance and normative commitment to the organization'. Fournal of Occupational Psychology, 63, 1-18.

Appelbaum, E., Bailey, T., Berg, P. and Kalleberg, A. (2000). Manufacturing Advantage: Why High-Performance Work Systems Pay off. Ithaca, NY: Cornell University Press.

Armstrong-Stassen, M. and Ursel, N. D. (2009). 'Perceived organizational support career satisfaction and the retention of older workers'. Fournal of Occupational and Organizational Psychology, 82, 210-20.

Arthur, J. B. and Boyles, T. (2007). 'Validating the human resource system structure: a levels-based strategic HRM approach'. Human Resource Management Review, 17, 77-92.

Bal, P. M., De Jong, S. B., Jansen, P. G. W. and Bakker, A. B. (2012). 'Motivating employees to work beyond retirement: a multi-level study of the role of I-deals and unit climate'. Fournal of Management Studies, $\mathbf{4 9 ,}$ 306-31.

Baltes, P. B. (1997). 'On the incomplete architecture of human ontogeny. Selection optimization and compensation as foundation'. American Psychologist, 52, 366-80.

Baltes, P. B., Staudinger, U. M. and Lindenberger, U. (1999). 'Lifespan psychology: theory and application to intellectual functioning'. Annual Review of Psychology, 50, 471-507.

Blau, P. M. (1964). Exchange and Power in Social Life. New York: John Wiley and Sons.

Bliese, P. D. (1998). 'Group size, ICG values, and group-level correlations: a simulation'. Organizational Research Methods, 1, 355-73.

Boxall, P. and Macky, K. (2009). 'Research and theory on high-performance work systems: progressing the high-involvement stream'. Human Resource Management fournal, 19, 3-23.

Boxall, P. and Purcell, J. (2011). Strategy and Human Resource Management, 3rd edition. Hampshire: Palgrave MacMillan.

Casper, W.J. and Harris, C. M. (2008). 'Work-life benefits and organizational attachment: self-interest utility and signalling theory models'. Fournal of Vocational Behavior, 72, 95-109.

Chen, G., Gully, S. M. and Eden, D. (2001). 'Validation of a new general self-efficacy scale'. Organizational Research Methods, 4, 62-83.

Christian, M. S., Garza, A. S. and Slaughter, J. E. (2011). 'Work engagement: a quantitative review and test of its relations with task and contextual performance'. Personnel Psychology, 64, 89-136.

Combs, J., Liu, Y., Hall, A. and Ketchen, D. (2006). 'How much do high-performance work practices matter? A meta-analysis of their effects on organizational performance'. Personnel Psychology, 59, 501-28.

Cumming, E. and Henry, W. E. (1961). Growing Old: The Process of Disengagement. New York: Basic Books.

De Jong, A., De Ruyter, K. and Lemmink, J. (2005). 'Service climate in self-managing teams: mapping the linkage between team member perceptions and service performance outcomes in a business-to-business setting'. Journal of Management Studies, 42, 1593-620.

Delery, J. E. and Doty, D. H. (1996). 'Modes of theorizing in strategic human resource management: tests of universalistic contingency and configurational performance predictions'. Academy of Management Journal, 39, 802-35.

Ebner, N. C., Freund, A. M. and Baltes, P. B. (2006). 'Developmental changes in personal goal orientation from young to late adulthood: from striving for gains to maintenance and prevention of losses'. Psychology and Aging, 21, 664-78.

Edgar, F. and Geare, A. (2005). 'HRM practice and employee attitudes: different measures - different results'. Personnel Review, 34, $534-49$.

Fornell, G. and Larcker, D. F. (1981). 'Evaluating structural equation models with unobservable variables and measurement error'. Fournal of Marketing Research, 18, 39-50.

Glöckner-Rist, A. and Hoijtink, H. (2003). 'The best of both worlds: factor analysis of dichotomous data using item response theory and structural equation modeling'. Structural Equation Modeling, 10, 544-65.

Guest, D. (1998). 'Is the psychological contract worth taking seriously?'. Journal of Organizational Behavior, 19, 649-64.

Guest, D. E. (1999). 'Human resource management - the workers' verdict'. Human Resource Management Journal, 9, 5-25.

Guest, D. E. (2011). 'Human resource management and performance: still searching for some answers'. Human Resource Management Fournal, 21, 3-13.

Guest, D. E. and Conway, N. (2002). 'Communicating the psychological contract: an employer perspective'. Human Resource Management fournal, 12, 22-38. 
Guthrie, J. P. (2001). 'High-involvement work practices, turnover, and productivity: evidence from NewZealand'. Academy of Management fournal, 44, 180-90.

Guzzo, R. A. and Noonan, K. A. (1994). 'Human resource practices as communications and the psychological contract'. Human Resource Management, 33, 447-62.

Harrison, D. A., Newman, D. A. and Roth, P. L. (2006). 'How important are job attitudes? Meta-analytical comparisons of integrative behavioral outcomes and time sequences'. Academy of Management Fournal, 49, 305-25.

Harter, J. K., Schmidt, F. L. and Hayes, T. L. (2002). 'Business-unit-level relationship between employee satisfaction, employee engagement, and business outcomes: a meta-analysis'. Fournal of Applied Psychology, 87, 268-79.

Hox, J. (2002). Multilevel Analysis. Techniques and Applications. Mahwah, NJ: Erlbaum.

Hu, L. and Bentler, P. M. (1999). 'Cutoff criteria for fit indexes in covariance structure analysis: conventional criteria versus new alternatives'. Structural Equation Modeling, 6, 1-55.

Jensen, J. M., Patel, P. C. and Messersmith, J. G. (in press). 'High-performance work systems and job control: consequences for anxiety, role overload, and turnover intentions'. Fournal of Management, doi: 10.1177/ 0149206311419663.

Jiang, K., Lepak, D. P., Hu, J. and Baer, J. C. (2012). 'How does Human Resource Management influence organizational outcomes? A meta-analytic investigation of mediating mechanisms'. Academy of Management fournal, 55, $1264-94$.

Jöreskog, K. and Sörbom, D. (2008). Lisrel 8.80. Chicago, IL: Scientific Software International.

Kaufman, B. and Miller, B. (2011). 'The firm's choice of HRM practices: economics meets strategic human resource management'. Industrial and Labor Relations Review, 64, 526-57.

Kehoe, R. R. and Wright, P. M. (2013). 'The impact of high performance HR practices on employees' attitudes and behaviors'. Fournal of Management, 39, 366-91.

Kinnie, N., Hutchinson, S., Purcell, J., Rayton, B. and Swart, J. (2005). 'Satisfaction with HR practices and commitment to the organisation: why one size does not fit all'. Human Resource Management Fournal, 15 , 9-29.

Klein, H.J., Molloy, J. C. and Brinsfeld, C. T. (2012). 'Reconceptualizing workplace commitment to redress a stretched construct: revisiting assumptions and removing confounds'. Academy of Management Review, 37, $130-51$.

Klein, K. J., Bliese, P. D., Kozlowski, S. W. J., Dansereau, F., Gavin, M. B., Griffin, M. A., Hofmann, D. A., James, L. R., Yammarino, F. J. and Bligh, M. C. (2000). 'Multilevel analytical techniques: commonalities differences and continuing questions'. In Klein, K. J. and Kozlowski, S. (Eds), Multilevel Theory Research and Methods in Organisations. San Francisco, CA: Jossey-Bass, 531-51.

Kooij, D. T. A. M., Jansen, P. G. W., Dikkers, J. S. E. and De Lange, A. H. (2010). 'The influence of age on the associations between HR practices and both affective commitment and job satisfaction: a meta-analysis'. Fournal of Organizational Behavior, 31, 1111-36.

Kuvaas, B. (2008). 'An exploration of how the employee-organization relationship affects the linkage between perception of developmental human resource practices and employee outcomes'. Fournal of Management Studies, 45, 1-25.

Lai, L., Rousseau, D. M. and Chang, K. T. T. (2009). 'Idiosyncratic deals: coworkers and interested third parties'. Fournal of Applied Psychology, 94, 547-56.

LeBreton, J. M. and Senter, J. L. (2008). 'Answers to 20 questions about interrater reliability and interrater agreement'. Organizational Research Methods, 11, 815-52.

Lepak, D. P. and Snell, S. A. (1999). 'The human resource architecture: toward a theory of human capital allocation and developmental'. Academy of Management Review, 24, 31-48.

Lindell, M. K. and Whitney, D. J. (2001). 'Accounting for common method variance in cross-sectional designs'. Fournal of Applied Psychology, 86, 114-21.

Mathieu, J. E. and Taylor, S. R. (2007). 'A framework for testing meso-mediational relationships in organizational behavior'. Fournal of Organizational Behavior, 28, 141-72.

Millward, L. J. and Hopkins, L. J. (1998). 'Organizational commitment and the psychological contract'. Fournal of Applied Social Psychology, 28, 1530-56.

Paauwe, J. (2009). 'HRM and performance: achievements, methodological issues and prospects'. Fournal of Management Studies, 46, 129-42.

Purcell, J. (1999). 'Best practice and best fit: chimera or cul-de-sac?'. Human Resource Management Fournal, 9, 26-41.

Raja, U., Johns, G. and Ntalianis, F. (2004). 'The impact of personality on psychological contracts'. Academy of Management fournal, 47, 350-67. 
Rasbash, J., Browne, W., Healy, M., Cameron, B. and Charlton, G. (2000). Mlwin Version 2.1: Interactive Software for Multilevel Analysis. London: Multilevel Models Project Institute of Education University of London.

Remery, G., Henkens, K., Schippers, J. and Ekamper, P. (2003). 'Managing an aging workforce and a tight labor market: views held by Dutch employers'. Population Research and Policy Review, 22, 21-40.

Rousseau, D. M. (1990). 'New hire perceptions of their own and their employer's obligations: a study of psychological contracts'. Fournal of Organizational Behavior, 11, 389-400.

Rousseau, D. M. (1995). Psychological Contracts in Organizations: Understanding Written and Unwritten Agreements. Thousand Oaks, CA: Sage Publications.

Rousseau, D. M. (2005). I-Deals: Idiosyncratic Deals Employees Bargain for Themselves. New York: M.E. Sharpe.

Rousseau, D. M. (2011). 'Reinforcing the micro/macro bridge: organizational thinking and pluralistic vehicles'. Fournal of Management, 37, 429-42.

Rousseau, D. M. and Parks, J. M. (1993). 'The contracts of individuals and organizations'. In Cummings, L. L. and Staw, B. M. (Eds), Research in Organizational Behavior. Greenwich, CT: JAI Press, Vol. 15, 1-43.

Schaufeli, W. B. and Bakker, A. B. (2004). 'Job demands, job resources, and their relationship with burnout and engagement: a multi-sample study'. Fournal of Organizational Behavior, 25, 293-315.

Shore, L. M. and Shore, T. H. (1995). 'Perceived organizational support and organizational justice'. In Cropanzano, R. and Kacmar, K. M. (Eds), Organizational Politics, Fustice and Support: Managing Social Climate at Work. Westport, CT: Quorum Press, 149-64.

Shore, L. M., Tetrick, L. E., Lynch, P. and Barksdale, K. (2006). 'Social and economic exchange: construct development and validation'. Fournal of Applied Social Psychology, 36, 837-67.

Shultz, K. S. and Wang, M. (2011). 'Psychological perspectives on the changing nature of retirement'. American Psychologist, 66, 170-9.

Siemsen, E., Roth, A. and Oliveira, P. (2010). 'Common method bias in regression models with linear, quadratic, and interaction effects'. Organizational Research Methods, 13, 456-76.

Snape, E. and Redman, T. (2010). 'HRM practices, organizational citizenship behaviour, and performance: a multilevel analysis'. Fournal of Management Studies, 47, 1219-47.

Song, L. J., Tsui, A. S. and Law, K. S. (2009). 'Unpacking employee responses to organizational exchange mechanisms: the role of social and economic exchange perceptions'. Fournal of Management, 35, 56-93.

Tabachnik, B. G. and Fidell, L. S. (2007). Using Multivariate Statistics, 5th edition. Boston, MA: Pearson.

Uebersax, J. S. (2006). The Tetrachoric and Polychoric Correlation Coefficients. Statistical Methods for Rater Agreement. Available at http://www.john-uebersax.com/stat/tetra.htm\#tsoft (accessed 19 January 2012).

Van De Voorde, K., Paauwe, J. and Van Veldhoven, M. (2010). 'Predicting unit performance using employee surveys: monitoring HRM-related changes'. Human Resource Management Fournal, 20, 44-63.

Veld, M., Paauwe, J. and Boselie, P. (2010). 'HRM and strategic climates in hospitals does the message come across the ward level?'. Human Resource Management fournal, 20, 339-56.

Waldman, J., Deane, K., Aurora, S. and Smith, L. (2004). 'The shocking cost of turnover in health care'. Health Care Management Review, 29, 2-7.

Whitman, D. S., Van Rooij, D. L. and Viswesvaran, C. (2010). 'Satisfaction, citizenship behaviors, and performance in work units: a meta-analysis of collective construct relations'. Personnel Psychology, 63, 41-81.

Wiese, B. S., Freund, A. M. and Baltes, P. B. (2000). 'Selection optimization and compensation: an action-related approach to work and partnership'. Fournal of Vocational Behavior, 57, 273-300.

Wiese, B. S., Freund, A. M. and Baltes, P. B. (2002). 'Subjective career success and emotional well-being: longitudinal predictive power of selection optimization and compensation'. Fournal of Vocational Behavior, 60, 321-35.

Wright, P. M., Gardner, T. M., Moynihan, L. M., Park, H. J., Gerhard, B. and Delery, J. E. (2001). 'Measurement error in research on human resources and firm performance: additional data and suggestions for future research'. Personnel Psychology, 54, 875-901.

Zaleska, K. J. and De Menezes, L. M. (2007). 'Human resources developmental practices and their association with employee attitudes: between traditional and new careers'. Human Relations, 60, 9871018.

Zhang, X., Cao, Q. and Tjosvold, D. (2011). 'Linking transformational leadership and team performance: a conflict management approach'. Fournal of Management Studies, 48, 1586-611.

Zhao, H., Wayne, S., Glibkowski, B. and Bravo, J. (2007), 'The impact of psychological contract breach on work-related outcomes: a meta-analysis'. Personnel Psychology, 60, 647-80. 